\title{
CATCHING THE THIEF: NeCTAR ROBBING BEHAVIOUR BY BUMBLEBEES ON NATURALISED FUCHSIA MAGELLANICA IN IRELAND
}

\author{
Dara A. Stanley ${ }^{* 1,2} \&$ Emmeline Cosnett ${ }^{1}$ \\ ${ }^{1}$ Botany and Plant Science, School of Natural Sciences, National University of Ireland Galway, Ireland \\ ${ }^{2}$ School of Agriculture and Food Science, University College Dublin, Belfield, Dublin 4, Ireland
}

\author{
Journal of Pollination Ecology, \\ 29(18), 2021, pp 240-248 \\ DOI: $10.26786 / 1920-$ \\ $7603(2021) 620$
}

Received 10 June 2020, accepted 20 August 2021 *Corresponding author: darastanley@gmail.com

\begin{abstract}
Fuchsia magellanica (Ongaraceae) is a plant with a traditionally ornithopholous pollination system, pollinated primarily by hummingbirds in its native range. As a naturalised alien plant in Ireland, F. magellanica is visited largely by bumblebees, with evidence for nectar robbing behaviour of the long-tubed flowers. We aimed to investigate nectar robbing behaviour of bumblebees on $F$. magellanica, and in particular whether floral and pollinator traits (size) determined likelihood of nectar robbing. While F. magellanica was visited by a number of bumblebee species, only two with shorter tongue lengths were observed to rob nectar from flowers. Although there was no observed relationship between intraspecific bee body size and nectar robbing behaviour, nectar robbing was observed most frequently in the site with the highest number of bees. Proportions of robbed flowers were low overall and varied between populations, but there was a significant relationship between flower size and whether it was nectar robbed with larger flowers robbed more often. Our work suggests that floral size determines whether a flower-visitor will choose to nectar rob or not in this system. Nectar robbing may also be related to bee density which could suggest this behaviour is driven by competition for resources, or that it is learnt by observing other bees.
\end{abstract}

Keywords-Bumblebee behaviour, nectar robbing, competition, pollination, floral larceny

\section{INTRODUCTION}

Faegri and Van der Pijl (1966, p. 68): "The distinction between simple theft and house-breaking exists in pollination ecology, too; thieves that cannot creep into the flower and steal nectar that way, may bite a hole through the perianth and get at it from the outside"

Plants and the pollinators that visit them have co-evolved over long time periods (Ollerton 2017), resulting in some examples of extreme specialisation between both groups (e.g. Arditti et al. 2012; Weinstein \& Graham 2017). The majority of flower-visiting insects visit flowers to feed on nectar and pollen, where many also provide valuable pollination services to plants (Ollerton et al. 2011). However, although many flower visitors visit flowers "legitimately" by coming into contact with the reproductive organs without damaging the flower, some flowers may be prone to having nectar "robbed" from them without the visitor coming into contact with the reproductive parts (Inouye 1980) which can have consequences for plant pollination (Irwin \& Maloof 2002). While nectar robbing can happen in various ways, the majority occurs when a flower visitor makes a hole in the perianth of a flowers to access nectar without "legitimately" visiting the flower (Inouye 1980). Primary nectar robbers are visitors that make the robbing hole themselves, whereas secondary robbers are those that use pre-existing holes (Inouye 1980).

Evidence suggests that both plant and flowervisitor traits could play a role in the likelihood of nectar robbing occurrence, particularly the morphological fit between flower and visitor. For plants, those with long flowers and abundant nectar are more likely to be robbed (Rojas-Nossa et al. 2016). This may occur as nectar robbers are unable to legitimately access the nectar within due to morphological constraints, and robbing results in a large reward. For flower-visitors, visitor size 
may also influence the ability of individuals to legitimately visit flowers. This can occur at the species level and some bumblebee species are known to rob because their tongue is simply too short to access nectar legitimately (Irwin \& Brody 1998), but it can also happen at the individual level and a negative relationship between intra-specific tongue length and nectar robbing behaviour has also been recorded (e.g. in Bombus terrestris; Valdivia et al. 2016). However, some flower-visitor species may act as nectar robbers in situations where morphological fit also allows them to visit legitimately, presumably as the effort of robbing has a high pay off for the robber in terms of reward (Dedej \& Delaplane 2005; Irwin \& Maloof 2002) although this may not always be the case (Lichtenberg et al. 2018). Nonetheless, more work is needed to understand the relationships between floral and flower-visitor traits, and nectar robbing behaviour.

Fuchsia magellanica Lam. (Onagraceae) is a plant species originally from South America, with a long purple corolla tube containing nectar, and bright red sepals. It is a classically ornithopholous flower, and is primarily pollinated by hummingbirds in its native range with some additional visits from bumblebees (Smith-Ramirez 1993; Traveset et al. 1998). In its native range it can also experience some nectar robbing by a fringillid bird (Phrygilus patagonicus; Traveset et al. 1998) and a non-native short-tongued bumblebee, Bombus terrestris L. (Valdivia et al. 2016). Fuchsia magellanica was initially planted in Ireland as an ornamental plant in the $19^{\text {th }}$ century and is now naturalised countrywide, but especially in the south, west and north (National Biodiversity Data Centre 2020). Although F. magellanica is self-compatible, autogamy rates can be low in its native range (Riveros 1991), and anecdotal observations in Ireland suggest that the species here is a cultivar "ricartonii" that does not produce viable seed, thereby deeming any interactions with floral visitors as commensal on behalf of the visitor. In the absence of hummingbirds in Ireland, casual observations suggest $F$. magellanica is primarily visited by bumblebee species but that the flowers are frequently "robbed".

Here, we investigate nectar robbing in an alien plant species, F. magellanica in Ireland, and whether there are associations between floral and bumblebee-visitor traits such flower and bee size and nectar robbing behaviour (Inoue et al. 2007; Navarro \& Medel 2009). In addition, we know that bumblebees can learn nectar robbing behaviour from other individuals of the same species (Leadbeater \& Chittka 2008), so nectar robbing may be driven by prior experience and observations of others performing the same behaviour, which could cause variations in robbing per site and season. Therefore, we set out to answer the following questions:

1) What are the most abundant bumblebee species visiting F. magellanica in Ireland, both legitimately and as robbers, and does bumblebee visitor abundance vary over time?

2) What is the extent to which F. magellanica flowers are robbed, and does this vary between sites?

3) Is there a difference in size between bees that rob F. magellanica and those that visit legitimately (i.e. are smaller bees more prone to robbing)?

4) Is there a relationship between flower size and robbing behaviour; i.e. are larger flowers robbed more frequently?

\section{MATERIALS AND METHODS}

Eleven sites were selected across the west and midlands of Ireland where F. magellanica was found growing, including a mixture of urban and rural areas (Fig. 1). We aimed to visit each site three times: once in July, once in August and once in October. One site (West Cork) was only visited in July, while a second (Westport) was only visited in August and October, resulting in 10 sites surveyed in July and August. In October, some sites had finished flowering and so either a nearby $F$. magellanica plant still in flower was chosen (four sites) or no data were collected (three sites; Table S1).

During each site visit, focal observations were carried out to estimate visitation rates of bumblebees to flowers and to quantify any nectar robbing behaviour observed. Two patches of flowers (containing 35 flowers each) were observed for 20 minutes at each site on each visit. Every bumblebee visitor entering the patch during the observation time was identified, as well as whether the individual was legitimately visiting a 


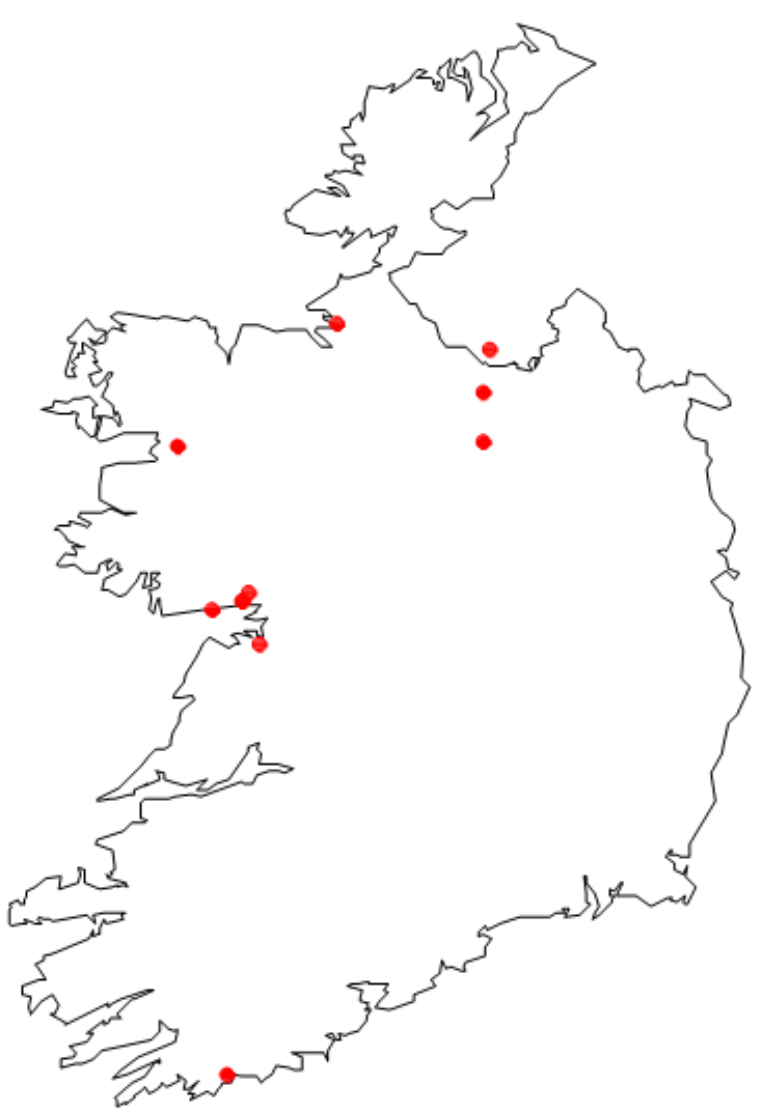

Figure 1. The 11 sampling sites used in the study around the west of Ireland. The closest two sites (Chapel and River Corrib) were $250 \mathrm{~m}$ apart and so are not differentiated here.

flower or nectar robbing, whether it collected nectar, pollen or both, and the number of flowers visited. Workers of B. terrestris and Bombus lucorum agg. were grouped as morphological identification is not reliable in the field (Carolan et al. 2012). Observations were carried out in dry, bright conditions (temperatures $11-18^{\circ} \mathrm{C}$ and wind $<4$ on Beaufort scale). Bumblebee abundance was compared between species (abundance pooled per species per site, with $N=11$ for each species) and sites (abundance pooled per site per sample period, with $N=10$ for July and August and $n=7$ for October) using Kruskall-Wallis tests as data did not meet parametric assumptions. Bees were only observed nectar robbing at one site in low numbers, and so nectar robbing data are presented graphically but not analysed statistically (Fig. 4).

Following the focal observations, a further 40 minutes was spent collecting bee morphology data on each site visit to assess whether there were any relationships between bee size and nectar robbing behaviour. Bees observed robbing or legitimately visiting flowers were caught using a sweep net and were placed in an insect plunger to hold them still. The inter-tegular wingspan ( $\mathrm{mm})$ of each individual was then measured using a Vernier calliper to two decimal places. As sample sizes of bumblebees collected robbing were small, patterns are tabulated but not analysed statistically (Table 1).

To record flower size and percentage of robbed flower in each site, the intactness (robbed or unrobbed) and petal length ( $\mathrm{mm}$ ) was measured of twenty flowers collected at random at each site on each visit using Vernier callipers. Petal length was used as a proxy for overall flower size as it was highly correlated with all other flower variables measured in a pilot study (nectary length, sepal length, stigma length, stamen length, ovary length and total length, Spearmans Rank Correlation $P<$ $0.05)$, except petal width. The proportion of robbed flowers at each site, and the variation between time periods, is present graphically (Fig. 5). The relationship between petal length and whether a flower was robbed or unrobbed was analysed using a linear mixed effects model in the nlme package (Pinheiro et al. 2012) in R v. 3.5.1 (R Core Team 2016), with each data point a flower and site as a random factor. The model was validated by inspecting qq-plots and histograms of residuals, and plotting standardized residuals versus fitted values.

Table 1. Inter-tegular width of bumblebees observed legitimately visiting $F$. magellanica flowers, and robbing them. ${ }^{*}$ Mean tongue lengths are taken from Goulson \& Darvill (2004)

\begin{tabular}{lrrr}
\hline Species & $\begin{array}{r}\text { Inter-tegular width } \\
\text { legitimate }(N)\end{array}$ & $\begin{array}{r}\text { Inter-tegular width } \\
\text { robbing }(N)\end{array}$ & $\begin{array}{r}\text { Mean tongue } \\
\text { length }(\mathrm{mm})^{*}\end{array}$ \\
\hline B. hortorum & $4.35(N=13)$ & $N A$ & 12.9 \\
B. lucorum & $4.1(N=9)$ & $4.19(N=6)$ & 7.9 \\
B. pascuorum & $3.14(N=88)$ & $3.37(N=1)$ & 8.5 \\
\hline
\end{tabular}


Nectar quantity (g) was measured in a subset of four of the sites closest to the lab. All nectar was extracted from the flowers using a microcapillary tube which was weighed using a fine balance scale to estimate nectar quantity. Nectar sugar percentage was taken from four sites in the first sampling round, but from all sites during the second round. Nectar sugar percentage was obtained using a refractometer from an average of six separate flowers at each site.

\section{RESULTS}

Five bumblebee species were observed visiting F. magellanica. Across all sampling periods, the most abundant bumblebee visitor was Bombus pascuorum Scopoli, whose numbers were significantly higher than the next most common species Bombus hortorum L. and Bombus lucorum agg. $\left(X^{2}=16.58, \mathrm{df}=2, P=0.00025\right.$; Figs. $\left.2 \& 3\right)$. $B$. hortorum was the largest of the observed bees which we know from the literature has the longest tongue (Goulson \& Darvill 2004), and was followed in tongue length by $B$. lucorum agg. (short-tongued) and B. pascuorum (mediumtongued; Table 1). Bumblebee visitor abundance varied between time periods $\left(X^{2}=10.54, \mathrm{df}=2, P=\right.$ 0.005), with highest abundances in August followed by July and October. Most bumblebee visitors legitimately visited flowers and robbing behaviour was only observed at one site (River Corrib) by both B. lucorum agg. and B. pascuorum, where numbers of $B$. lucorum agg. recorded (22 individuals in August) were much higher than any other sampling period in any other site (next highest $=8$ individuals). Most of these nectar robbing observations were in August, although one was also seen in July, and both species were also observed legitimately visiting at the same site (Fig. 4).

Robbed F. magellanica flowers were recorded in eight sites. Overall, proportions of robbed flowers were low $($ mean $=11 \%$, range $=2-25 \%$ ), although the extent of nectar robbing varied among sites and months (Fig. 5). Bees observed robbing did not differ in size to those that visited legitimately (Table 1), although as sample sizes were small and robbing behaviour was only observed at one site statistical analysis could not be completed. Although not recorded, honeybees and wasps were also observed both legitimately visiting and robbing $F$. magellanica in a few sites on some sampling occasions; honeybees were less frequent visitors than bumblebees, but wasps were more abundant than bumblebees at some sites near the end of the season (August and October).
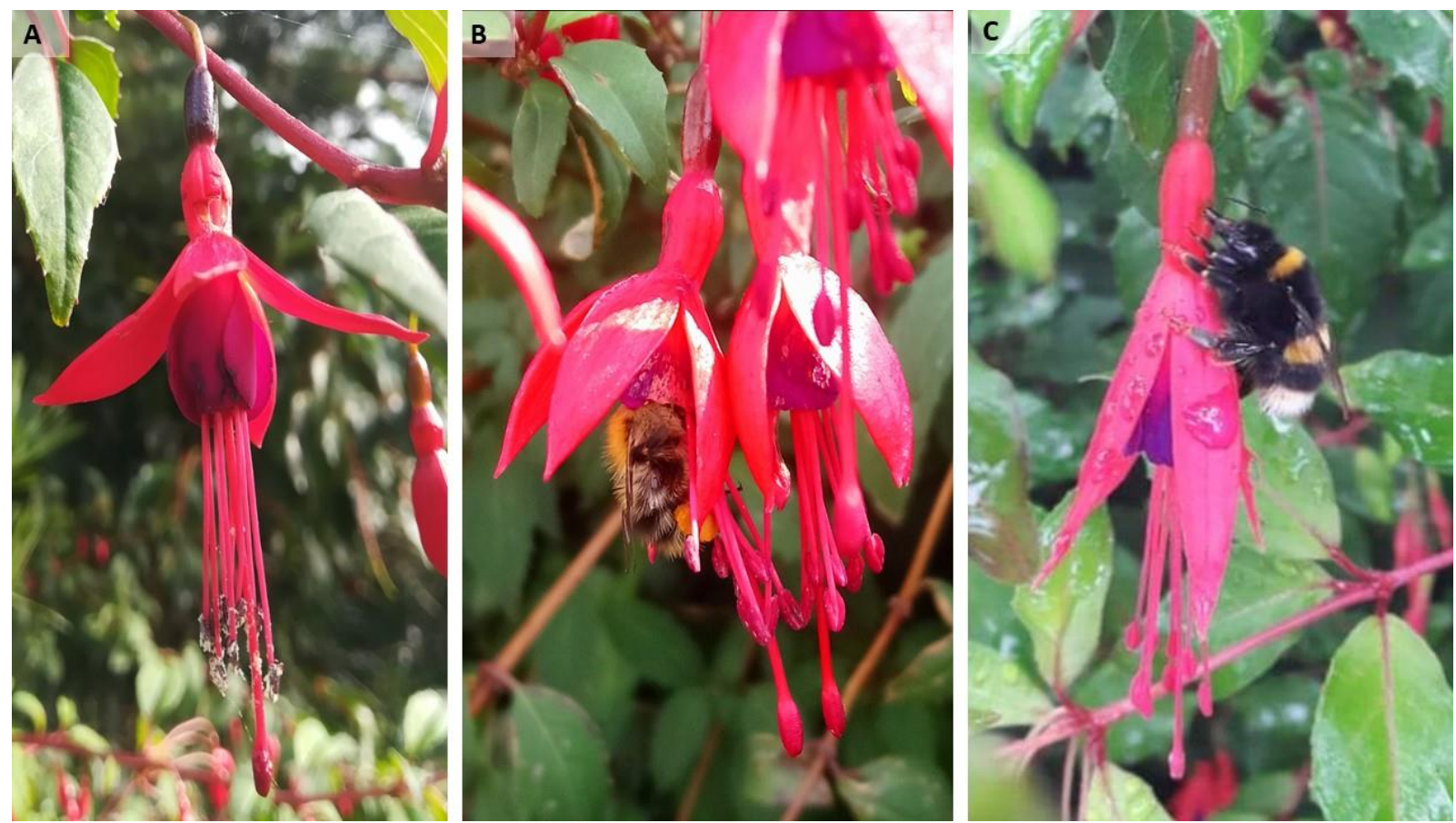

Figure 2. A) Fuchsia magellanica flower with a nectar robbing hole, B) Bombus pascuorum legitimately visiting F. magellanica and C) Bombus lucorum agg. nectar robbing F. magellanica. Photos EC and DS. 


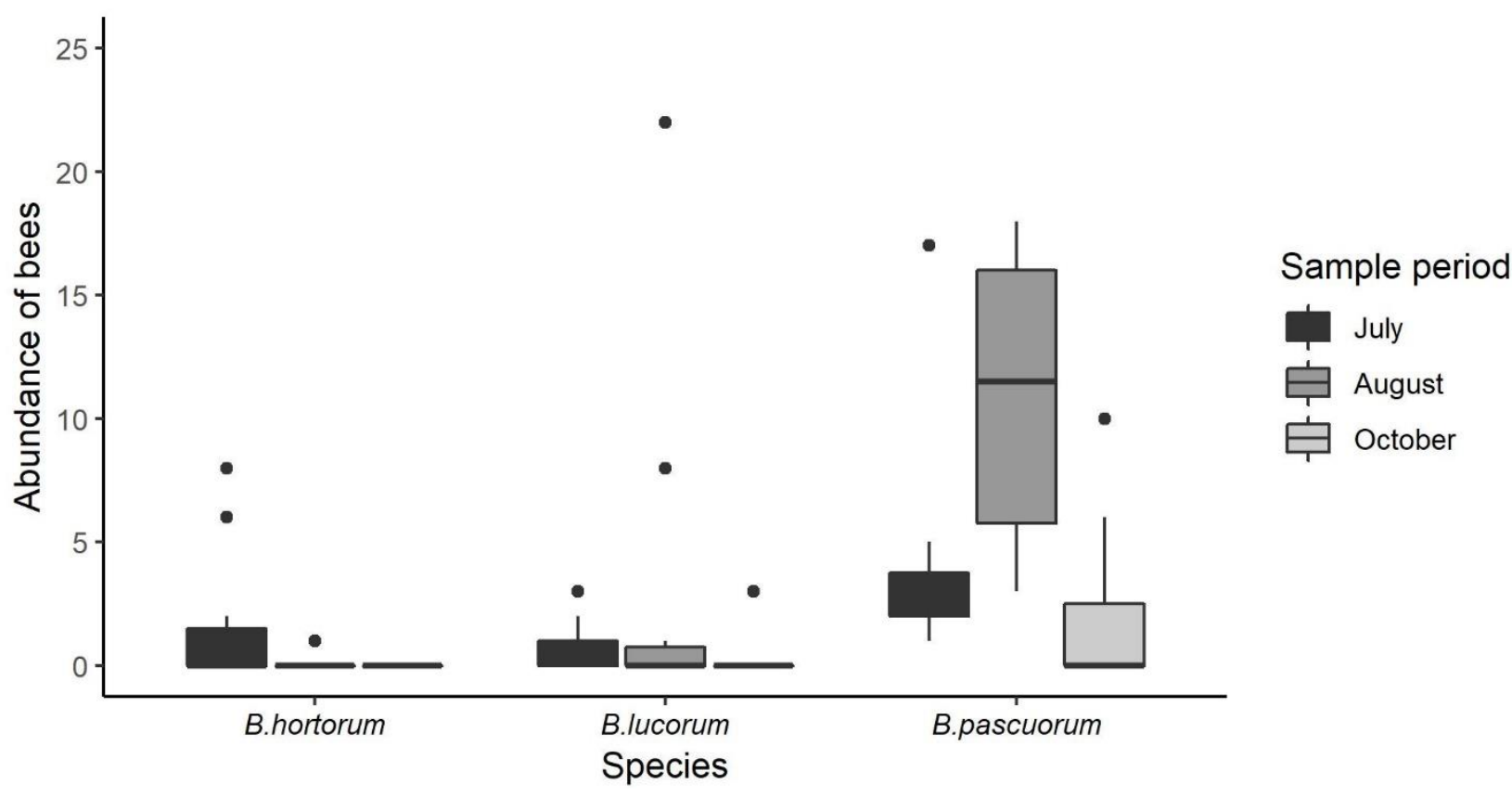

Figure 3. Boxplot showing the abundance of bumblebees observed visiting $F$. magellanica per site in each sampling period. Bombus jonellus and Bombus pratorum were also observed once each in the Sligo site in August, but were not included in further analyses.

F. magellanica flowers varied in size between sites (mean petal length per site $12.5 \mathrm{~mm}$, range 11$15 \mathrm{~mm})$. Fuchsia flowers that were robbed were larger than unrobbed flowers (Fig. 6; GLMM F1,568 $=44.35, P<0.0001)$. On average, nectar standing crop of $F$. magellanica flowers was $0.014 \mathrm{~g}(N=16$, range $=0.002-0.05)$ and sugar content was $19 \%(N$ $=127$, range $=3-42$ ).

\section{DISCUSSION}

Fuchsia magellanica is a naturalized, alien plant in Ireland. Although it has a classical ornithophilous pollination system and is visited primarily by hummingbirds in its native range, we have shown that in its naturalized range in Ireland it is visited mainly by bumblebees who use it as a forage resource through both legitimate and robbing visits. While floral traits (flower size) influenced likelihood of being robbed and robbing behaviour differed between bumblebee species, we found no evidence that intraspecific flowervisitor traits (body size) affected robbing behaviour.

Bumblebees were frequent visitors to $F$. magellanica in our system, and nectar robbing behaviour differed between species. We only observed robbing in the mid-shorter tongued bumblebee species (B. lucorum agg and $B$. pascuorum), and not the longer tongued $B$. hortorum (although fewer of this species were observed overall). This is consistent with the existing literature; a range of studies have shown that Hymenoptera, and in particular bees, are the most common primary robbers and also commonly use

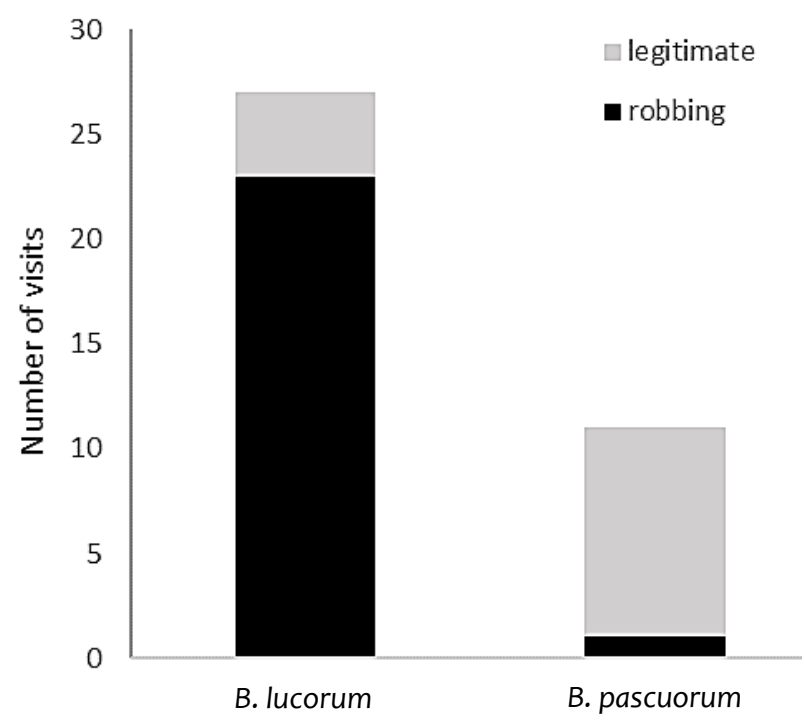

Figure 4. Nectar robbing behavior was only observed at one site: River Corrib. Two species were observed nectar robbing: the medium-tongued $B$. pascuorum and the shorttongued B. lucorum agg. 

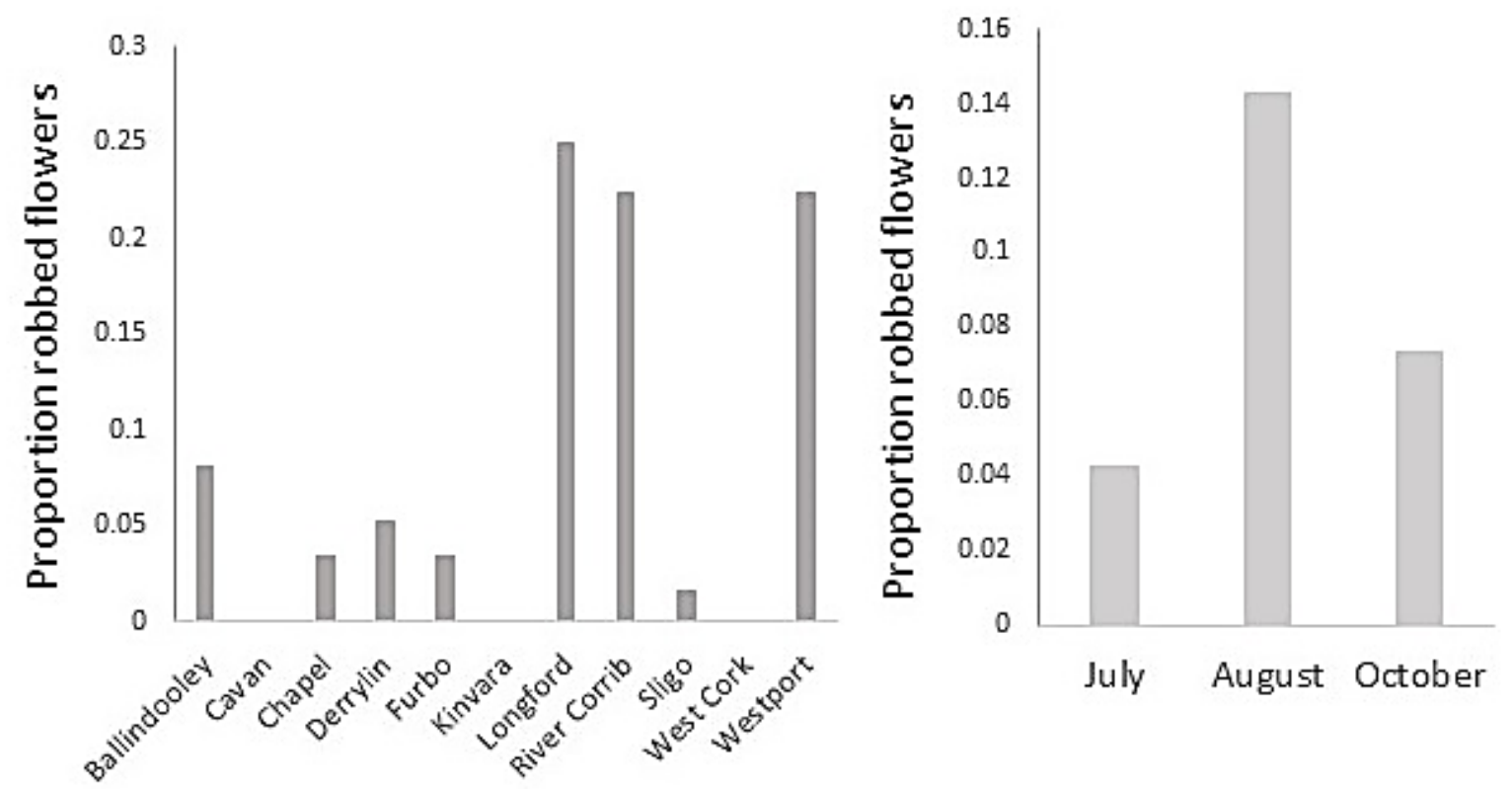

Figure 5. Proportion of all flowers that were robbed varied between (A) sites, and (B) sampling periods.

mixed foraging strategies (i.e. both robbing and legitimately visiting; Irwin et al. 2010). The mean perianth tube length of $F$. magellanica measured in this study $(11.7 \mathrm{~mm})$ is longer than the tongue length of both B. pascuorum and B. lucorum agg. (Table 1), but not that of $B$. hortorum. When visiting F. magellanica legitimately, the shorter tongued species appear to be straining to stick their head into the corolla tube to access nectar. This suggests that tongue-length may be a factor limiting legitimate visits from these species, suggesting nectar robbing may be an easier alternative strategy. Short-tongued bumblebees have also been observed to rob nectar in Linaria vulgaris in the UK, whereas long-tongued bees visited legitimately (Stout et al. 2000).

Incidence of nectar robbing in F. magellanica was low overall (max. 25\% flowers per site); this result was similar to that from a study looking at nectar robbing of $F$. magellanica by non-native bumblebees in its native range (Valdivia et al. 2016), but much lower than other studies that investigated other native plant species, in which almost all flowers in some populations can be robbed (Singh et al. 2014; Stout et al. 2000). However, we found variation in proportions of robbed flowers between sites and time periods, with no robbing at all recorded in some sites and differences in robbing among time periods. Few studies have looked at variation in robbing rates between populations and seasons (Irwin et al.
2010) although Valdivia et al. (2016) also found variation in nectar robbing between populations.

The proportion of robbed flowers in our study was highest in August, which is also when numbers of B. lucorum agg. and B. pascuorum were highest, and we also observed robbing behaviour most frequently in the site with the highest recorded numbers of $B$. lucorum agg. Large numbers of B. lucorum agg. visiting F. magellanica at this site may be driven by high densities of this species, or competition for resources in the surrounding area, both of which may drive a need

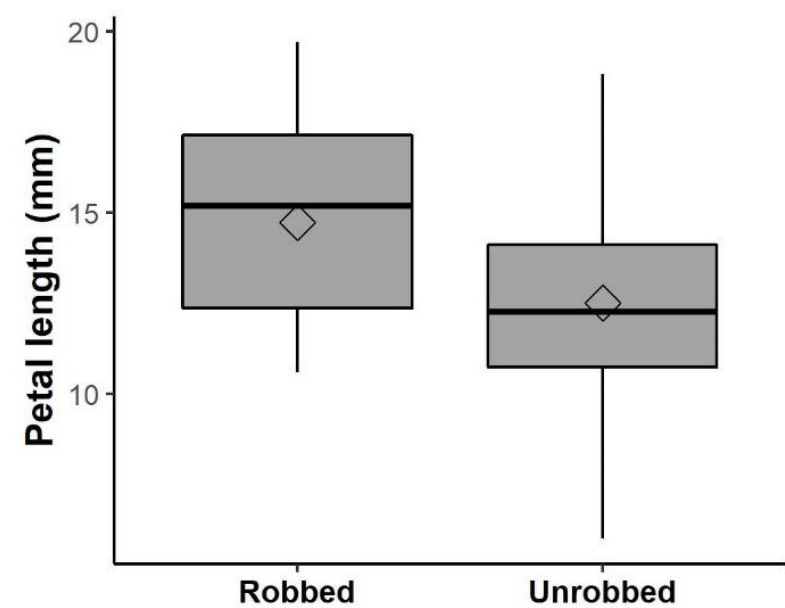

Figure 6. Boxplot of petal length (+/- SE) of flowers that were robbed (with a bitten hole in the corolla tube) or unrobbed across all sites. Diamonds represent mean values (unrobbed $N=535$, robbed $N=45$ ). 
for easy access to nectar which can be achieved through robbing by this short-tongued species but this deserves further research. Although, for the most part, we were not able to distinguish between primary and secondary robbing, all direct observations of B. pascuorum were of secondary robbers, while B. lucorum agg. was observed primary robbing. All this may suggest that $B$. lucorum agg. is the key primary robber of this plant, but more data is needed to confirm this and it would be interesting to quantify the rates of primary vs secondary robbing and determine what might be driving these interactions (Irwin et al. 2010). We also know that bumblebees, in particular, can learn nectar robbing behaviour from each other (Leadbeater \& Chittka 2008), and so it may be that once a small number of individuals learn to rob at a certain site, the information passes through a number of individuals via social transmission thus increasing the behaviour.

Although sample sizes were too small to formally analyse, we did not observe an influence of intra-specific bee size on nectar robbing behaviour. Other work has found a significant relationship between bee size and nectar robbing with smaller bees robbing more frequently (Valdivia et al. 2016). This may suggest that there is less variation in bee body size in our system, or that other factors such as inter-specific interactions, availability of forage resources, or the variation in floral traits has a stronger effect on nectar robbing behaviour.

We found that larger flowers were more likely to be robbed, which suggests that floral traits, and more specifically the morphological "fit" between a flower visitor and flower, may be driving robbing behaviour. This is concurrent with existing literature that shows that plants with long flowers are more likely to be robbed (but see Irwin \& Maloof 2002; Navarro \& Medel 2009; RojasNossa et al. 2016). The long corolla of F. magellanica is variable in size in this system, and this coupled with the differences in tongue length of the different bumblebee species visitors may be influencing nectar robbing.

In this study, we chose to focus on bumblebees as the most frequent flower visitors to $F$. magellanica in Ireland. Although we directly observed some nectar robbing behaviour, this was relatively rare. However, both honeybees and wasps were also observed visiting $F$. magellanica flowers, both legitimately and via nectar robbing, with wasps being particularly abundant in October. We also observed a different size and shape of nectar robbing hole in October, which may indicate increased robbing by wasps which would be interesting to investigate further, especially since, historically, wasps have been recorded less often than bees as primary robbers (Irwin et al. 2010).

While we observed the frequency and drivers of nectar robbing, effects on plant reproduction were outside the scope of this study. Reports suggest that $F$. magellanica in Ireland rarely sets viable seed and mainly spreads vegetatively, but reproduction of this species in Ireland requires further investigation. The impacts of nectar robbing on seed and fruit set elsewhere are variable (Maloof \& Inouye 2000); for example, robbing can promote foraging and pollinator movement, thus increasing fruit set (Singh et al. 2014), or can negatively affect fruit set in a variety of ways, such as by damaging the flower, as has been demonstrated in F. magellanica following nectar robbing by birds (Traveset et al. 1998). However, many nectar-robbing interactions could be described as commensal with pollinators benefitting, but no impacts on reproduction of the plant (Heiling et al. 2018; Stout et al. 2000), and it would be interesting to test this in this system.

Nectar robbing occurs in many plant communities globally (Rojas-Nossa et al. 2016). Here we confirm that it also exists in F. magellanica in its non-native range in Ireland, and that there are relationships between floral size and likelihood of nectar robbing which suggests nectar robbing is driven by morphological constraints of bumblebees in the absence of hummingbird pollinators. In addition, we confirm that the naturalized alien F. magellanica is providing a nectar source for a variety of bumblebee species in Ireland. However, there is still more to learn about this system in terms of any impacts on plant reproduction, and the role of flower visitors other than bumblebees. This work adds to the growing literature on the ecology of nectar robbing globally (Irwin et al. 2010). 


\section{ACKNOWLEDGEMENTS}

We would like to thank Katherine Burns for comments on this manuscript, landowners for access to privately owned sites, and the following people who helped with data collection: Aaron Southgate, Susan Cosnett, Kate Greaney and Roisin Doherty.

\section{AUTHOR CONTRIBUTION}

Concept and design DS \& EC, data collection EC, data analysis DS, writing DS, edits and approval for publication DS \& EC

\section{APPENDICES}

Additional supporting information may be found in the online version of this article:

Table S1. Site visited, their location and the number of times they were visited

\section{REFERENCES}

Arditti J, Elliott J, Kitching IJ, Wasserthal LT (2012) 'Good Heavens what insect can suck it'- Charles Darwin, Angraecum sesquipedale and Xanthopan morganii praedicta. Botanical Journal of the Linnean Society 169:403-432

Carolan JC et al. (2012) Colour patterns do not diagnose species: quantitative evaluation of a DNA barcoded cryptic bumblebee complex. PLoS ONE 7:e29251

Dedej S, Delaplane KS (2005) Net energetic advantage drives honey bees (Apis mellifera L) to nectar larceny in Vaccinium ashei Reade. Behavioral Ecology and Sociobiology 57:398-403

Faegri K, Van der Pijl L (1966) The principles of pollination ecology, Oxford, England

Goulson D, Darvill B (2004) Niche overlap and diet breadth in bumblebees; are rare species more specialized in their choice of flowers? Apidologie 35:55-63

Heiling JM, Ledbetter TA, Richman SK, Ellison HK, Bronstein JL, Irwin RE (2018) Why are some plantnectar robber interactions commensalisms? Oikos 127:1679-1689

Inoue MN, Ushijima J, Yoyama J (2007) Effect of Weigela hortensis (Caprifoliaceae) floral morphology on pollinator behavior. Plant Species Biology 22:77-86

Inouye DW (1980) The terminology of floral larceny. Ecology 61:1251-1253

Irwin RE, Brody AK (1998) Nectar robbing in Ipomopsis aggregata: effects on pollinator behavior and plant fitness. Oecologia 116:519-527

Irwin RE, Bronstein JL, Manson JS, Richardson L (2010) Nectar robbing: ecological and evolutionary perspectives. Annual Review of Ecology, Evolution, and Systematics 41:271-292

Irwin RE, Maloof JE (2002) Variation in nectar robbing over time, space, and species. Oecologia 133:525-533

Leadbeater E, Chittka L (2008) Social transmission of nectar-robbing behaviour in bumble-bees. Proc. B 275:1669-1674

Lichtenberg EM, Irwin RE, Bronstein JL (2018) Costs and benefits of alternative food handling tactics help explain facultative exploitation of pollination mutualisms. Ecology 99:1815-1824

Maloof JE, Inouye DW (2000) Are nectar robbers cheaters or mutualists? Ecology 81:2651-2661

National Biodiversity Data Centre (2020) Fuchsia magellanica distribution - Biodiversity Maps, https://maps.biodiversityireland.ie/Species/29047

Accesssed 18th May 2020

Navarro L, Medel R (2009) Relationship between floral tube length and nectar robbing in Duranta erecta L. (Verbenaceae). Biological Journal of the Linnean Society 96:392-398

Ollerton J (2017) Pollinator diversity: distribution, ecological function, and conservation. Annual Review of Ecology, Evolution, and Systematics 48:353-376

Ollerton J, Winfree R, Tarrant S (2011) How many flowering plants are pollinated by animals? Oikos 120:321-326

Pinheiro J, Bates D, DebRoy S, Sarkar D, R Development Core Team (2012) Package "nlme": Linear and nonlinear mixed effects models. R package version 3.1104

R Core Team (2016) R: A language and environment for statistical computing. $\mathrm{R}$ Foundation for Statistical Computing, Vienna, Austria. URL http://www.Rproject.org

Rojas-Nossa SV, Sánchez JM, Navarro L (2016) Nectar robbing: a common phenomenon mainly determined by accessibility constraints, nectar volume and density of energy rewards. Oikos 125:1044-1055

Singh VK, Barman C, Tandon R (2014) Nectar robbing positively influences the reproductive success of Tecomella undulata (Bignoniaceae). PLOS ONE 9:e102607

Smith-Ramirez C (1993) Los picaflores y su recurso floral en el bosque templado de la isla de Chiloé, Chile. Revista Chilena de Historia Natural 66:65-73

Stout JC, Allen JA, Goulson D (2000) Nectar robbing, forager efficiency and seed set: Bumblebees foraging on the self-incompatible plant Linaria vulgaris (Scrophulariaceae). Acta Oecologica-International Journal of Ecology 21:277-283

Traveset A, Willson MF, Sabag C (1998) Effect of nectarrobbing birds on fruit set of Fuchsia magellanica in 
Tierra del Fuego: a disrupted mutualism. Functional Ecology 12:459-464

Valdivia CE, Carroza JP, Orellana JI (2016) Geographic distribution and trait-mediated causes of nectar robbing by the European bumblebee Bombus terrestris on the Patagonian shrub Fuchsia magellanica. Flora -
Morphology, Distribution, Functional Ecology of Plants 225:30-36

Weinstein BG, Graham CH (2017) Persistent bill and corolla matching despite shifting temporal resources in tropical hummingbird-plant interactions. Ecology Letters 20:326-335 